\title{
Modelling for Designing, Managing and Improving Virtual Enterprises in One-of-a-kind Business
}

\author{
Lauri Koskela, Abdul Samad Kazi, Matti Hannus \\ VTT Building Technology \\ PO Box 1801, FIN-02044 VTT, Finland \\ Em:lauri.koskela@vtt.fi
}

Keywords Production Theory, Virtual Enterprise, One-of-a-kind Production

\begin{abstract}
The paper starts with an exploration of the current conceptual underpinnings, paradigms and theories of production from the point of view of modelling. It is argued that modelling should bear on designing, controlling and improving production systems. Modelling should orient towards the existing three conceptual views on production: transformation, flow and value generation. Furthermore, modelling should cover both the physical process and the control information process. Finally, modelling should respond to the specific needs of virtual production in one-of-a-kind business, for example, the design of the production system accentuates. Two sets of modelling tools are analyzed against this framework: comprehensive modelling approaches and specific, more partial tools for virtual production. These results suggest that, at the level of research, the search for a unified conceptualization of production should be emphasized; only based on such a foundation can truly comprehensive and integrated modelling tools be constructed. At the more practical level, modelling efforts - in lack of tools based on a unified conceptualization - have to be partial; however, these efforts should be structured so that various modelling approaches could more easily be interfaced with each other, and the limitations of the particular tools in use should be clearly recognized.
\end{abstract}

\section{INTRODUCTION}

The goal of this presentation is to present a comprehensive view on the requirements to be set for modelling virtual enterprises in one-of-a-kind business, and thus to contribute to the definition of a generic architecture for these kinds of enterprises. This is essentially a background paper by nature and does not contain concrete proposals for a generic architecture. However, existing modelling methods are analyzed against the requirements set. 
The plan of the paper is as follows. First, we discuss modelling needs attributable to the purpose of modelling, namely design, control and improvement of the production system. Secondly, we treat the requirements with respect to different theories of production. Thirdly, requirements derived from the subject of modelling are derived. Next, we compare existing modelling methods to the set of requirements produced. Finally, we summarize our findings and discuss their implications.

\section{DIFFERENT LEVELS OF ANALYSIS OF PRODUCTION}

There are three generic actions, which we would like to be guided by modelling production:

- Design of the production system

- Control of the production system to get the intended production realized

- Improvement of the production system.

Production modelling efforts can be divided into two distinct classes: physical material focus vs. control data focus [10]. With physical material focus, the aim is to represent the product flow through the production facility (network). The purpose of modelling is to improve operations. In contrast, with control data focus, the aim is to represent the relationships and flows of control data and the data processing logic. The purpose of modelling is to improve information management so as to improve manufacturing processes.

Thus, in summary, we require that modelling is capable of representing the design, control and improvement of the production system. Also, both the physical flow and the control information flow should be covered.

\section{THEORIES OF PRODUCTION}

In the following, the novel TFV (Transformation, Flow, Value) framework of production, as presented in [12], is summarized.

The primary characteristic of a theory of production is that it should be prescriptive: it should reveal how action contributes to the goals set for production. Production has three kinds of goals. Firstly, the goal of getting the intended products produced in general (this may seem so self-evident that it is often not explicitly mentioned). Secondly, there are goals related to the characteristics of the production itself, such as cost minimization and level of utilization (internal goals). Thirdly, there are goals related to the needs of the customer, like quality and flexibility (external goals). 
Furthermore, the theory of production should cover all the essential areas of production, especially production proper and product design.

Throughout the 20th century, the transformation view of production has been dominant. In the transformation view, production is conceptualized as a transformation of inputs to outputs. There are a number of principles, by means of which production is managed. These principles suggest, for example, decomposing the total transformation hierarchically into smaller transformations, tasks, and minimizing the cost of each task independently. The conventional template of production has been based on it, as well as the doctrine of operations management. The transformation view has its intellectual origins in economics, where it has remained unchallenged up to this day. The popular value chain theory, proposed by Porter [16], is one approach embodying the transformation view. A production theory based directly on the original view on production in economics has been proposed by a group of scholars led by Wortmann [22].

However, this foundation of production is an idealization, and in complex production settings the associated idealization error becomes unacceptably large. There are two main deficiencies: it is not recognized that there are also other phenomena in production than transformations; it is not recognized that it is not the transformation itself that makes the output valuable, but that the output conforms with the customer's requirements. The transformation view is instrumental in discovering which tasks are needed in a production undertaking and in getting them realized. However, the transformation view is not especially helpful in figuring out how to ensure that the customer requirements are met in the best manner or how not to use resources unnecessarily. Therefore, production, managed in the conventional method, tends to become inefficient and ineffective.

There has existed, already in the framework of early industrial engineering, another concept of production, namely the view of production as flow. The flow view of production, firstly proposed by the Gilbreths [5] in scientific terms, has provided the basis for JIT (Just In Time) and lean production. This view was firstly translated into practice by Ford [3]; however, the template provided by Ford was in this regard misunderstood, and the flow view of production was further developed only from 1940'ies onwards in Japan, first as part of war production and then at Toyota. As a result, the flow view is embodied in lean production. In the flow view, the basic thrust is to eliminate waste from flow processes. Thus, such principles as lead time reduction, variability reduction and simplification are promoted. In a breakthrough book, Hopp and Spearman [7] show that by means of the queueing theory, various insights, which have been used as heuristics in the framework of JIT, can be mathematically proven. 
Still a third view on production has existed from the 1930'ies. In the value generation view, the basic thrust is to reach the best possible value from the perspective of the customer. The value generation view was initiated by Shewhart [21] and further refined in the framework of the quality movement but also in other circles. Principles related to rigorous requirements analysis and systematized flowdown of requirements, for example, are put forward. Cook [2] has recently presented a synthesis of a production theory based on the flow view.

Thus, there are three major concepts of production, and each of them has induced practical methods, tools and production templates. Nevertheless, except a few isolated endeavors, these concepts - as candidate theories of production - have raised little interest in the discipline of operations management. As stated above, there has not been any explicit theory of production. The consequential problem is that the important functions of a theory, as outlined, have neither from the viewpoint of research or practice been realized.

What, then, should be held as the theory of production? There are three partial theories, and because they have not yet been unified, we have to use them simultaneously. As argued at more length in [12], such a TFV theory of production provides a framework for analyzing production (Table 1).

Table 1. The framework for analyzing production, based on the TFV theory of production.

\begin{tabular}{llll}
\hline & Transformation view & Flow view & Value generation view \\
\hline $\begin{array}{l}\text { Design of } \\
\text { production }\end{array}$ & $\begin{array}{l}\text { What is the structure of } \\
\text { activity decomposition? }\end{array}$ & $\begin{array}{l}\text { What is the } \\
\text { structure of the } \\
\text { flow? }\end{array}$ & $\begin{array}{l}\text { What is the structure of } \\
\text { the value generation } \\
\text { process? }\end{array}$ \\
\hline $\begin{array}{l}\text { Control of } \\
\text { production }\end{array}$ & $\begin{array}{l}\text { How are production } \\
\text { resources allocated to } \\
\text { activities? }\end{array}$ & $\begin{array}{l}\text { How is the } \\
\text { productive flow } \\
\text { controlled? }\end{array}$ & $\begin{array}{l}\text { How is the stagewise } \\
\text { transformation of } \\
\text { requirements into } \\
\text { products controlled? }\end{array}$ \\
\hline $\begin{array}{l}\text { Improvement } \\
\text { of production }\end{array}$ & $\begin{array}{l}\text { How are activities } \\
\text { improved? }\end{array}$ & $\begin{array}{l}\text { How is the flow } \\
\text { performance } \\
\text { improved? }\end{array}$ & $\begin{array}{l}\text { How is the value } \\
\text { generation performance } \\
\text { improved? }\end{array}$ \\
\hline
\end{tabular}

\section{ONE-OF-A-KIND PRODUCTION BY VIRTUAL ENTERPRISES}

One-of-a-kind production is characterized by two issues [22, 18]. Firstly, product design is an integral part of production (that is, product design or development beyond mere selection of options or configuration design). Secondly, there is uncertainty, which is critical especially in regard 
to customer order acceptance. This uncertainty is, of course, caused by the lack of experience on the one-of-a-kind features of the product.

A virtual organization has been defined as a new customer-oriented and opportunity-based organizational model that uses technology to dynamically link people, assets, and ideas [6]. In a virtual organization, core competencies from several real organizations are integrated.

Thus, this kind of production sets several special requirements to modelling:

- product development and design is an integral part of production, and has to be modeled as a part of the production process

- design of the production system is crucial

- control of the production system is made difficult by the associated uncertainty

- improvement of the production system has to take place on-line; there are few possibilities for continuous, long-term improvement

- control information modelling accentuates in those cases where chunks of physical production are treated as black boxes.

\section{ADEQUACY OF CURRENT MODELLING METHODS}

\subsection{Introduction}

Are current modelling methods adequate in view of the requirements defined in the preceding section? This question is approached by analyzing representative examples, first, of comprehensive modelling tools, and, second, of partial modelling tools suitable for virtual, one-of-a-kind production.

\subsection{Comprehensive modelling tools}

A number of comprehensive process modelling tools have been developed in the 1990's. In the following, we discuss three of them: the enterprise engineering model, the electronic process handbook, and the unified process specification language. They all are purported, among other things, for design of production systems.

Enterprise engineering models, like GERAM, provide a generalized framework for describing the components needed in all types of enterprise engineering/integration processes, such as the formation of a virtual enterprise [4]. The development of these models has started from efforts to integrate industrial automation. Unfortunately, this background still seems to be a restricting factor. This is evident in the motivation for a standard in this area [8]: "A standard for enterprise models should enhance 
interoperability by establishing the elements that must be present in an enterprise model". Thus, although extended to enterprise engineering, the focus of this discipline is largely on integration, e.g. control information, rather than the physical process itself.

The initiative towards an electronic process handbook [14] is based on the functional view (this equals to transformation-centered view) on processes, but adds a number of important features. In addition to the hierarchical abstraction (decomposition-composition), the dimension of generalization and specialization is added to the description. Also, the types of dependencies between activities are analyzed. It is claimed that there are three types of basic dependencies: flow, sharing and fit. Flow dependency is basically the supplier-consumer relationship. Sharing dependencies occur when multiple activities use the same resource. Fit dependencies arise when multiple activities collectively produce a single resource. Coordination mechanisms for different types of dependencies are correspondingly analyzed and classified. The handbook is intended for redesigning existing organizational processes, inventing new processes and sharing ideas about organizational practices.

The National Institute of Standards and Technology (U.S.) is promoting a project developing a unified process specification language [20]. The motivation is to create a language by means of which various applications, ranging from project management to manufacturing process planning, could exchange information on processes, understood as collections of activities. Requirements for such a language have been grouped into four categories: core, outer core, extensions and application specific. Although the main focus is on manufacturing processes, product development processes are also covered.

All these three frameworks are new, and few, if any, practical applications exist. Analysis reveals that they all are biased towards the transformation model of production. Furthermore, the enterprise engineering model is mainly focused on control information, whereas the unified process language and the electronic process handbook are focused on the physical production process.

\subsection{Partial modelling tools}

\subsubsection{Tools based on the transformation model}

Generally, project management methods, like the Work Breakdown Structure (WBS) and critical chain network, provide examples of tools based on the transformation model. Such tools have been integrated into Simo-2 [13]. It consists of a modelling tool, a multi-user project planning and 
simulation package, and a separate analysis tool. Modelling divides into three phases: product, business and project modelling. First, all partners model the product structure. Then, each partner creates a business plan, that is, a non-public operational plan of how they will execute their part of the project. Then, project modelling can start: main and subcontracts are defined and the schedule created. Several users can co-operate in this phase for iteration of the contract structure and schedule. With all the models finished, the project can next be simulated to determine if all targets are being met.

However, this model is not without limitations, due to its conceptual basis. It is not possible to model the flow of information and material in detail by this model; also the interdependencies between different contracts are not treated. Likewise, design iteration cannot be modeled.

\subsubsection{Tools based on the flow model}

There are several generic tools that are based on the flow model, like IDEF3, Design Structure Matrix and the traditional flow analysis methods of industrial engineering. However, it has been a challenge to provide a userfriendly interface to such models. In this regard, Rose [19] describes an interesting tool called PROVE for engineering process representation and assessment. A visualization tool is used for animating process graph structures, and this animation offers the main interface vis-a-vis users. The process is primarily modeled in regard to activities and documents. This tool is used for process design from two view points. First, process assessment for judging the accuracy, performance and quality of the process and its description. Second, process synchronization for reconciling the contributions of related processes.

Again, there are limitations due both to the conceptual basis selected and to the fact that only parts of that conceptual basis have been realized. For example, in this PROVE model, it is not possible to model design iterations, neither it is possible to analyze the implications of value generation issues of the flow of the design process.

\subsubsection{Tools based on the value generation model}

Value-oriented modelling is well represented by requirements traceability, which refers to the ability to describe and follow the life of a requirement, in both a forward and backward direction, ideally through the whole systems life cycle [9]. Various commercial and in-house traceability models are currently in use, especially in high-tech domains [17]. Maybe the oldest generic traceability tool is Quality Function Deployment (QFD) [1]. 
Such traceability models support the design, control and improvement of the product realization process from the value point of view. Again, natural limitations of value-oriented models can be recognized: they are not very helpful for managing activities or flows.

\section{CONCLUDING DISCUSSION}

It has been argued that modelling should bear on designing, controlling and improving production systems. Modelling should orient towards the existing three conceptual views on production: transformation, flow and value generation. Furthermore, modelling should cover both the physical process and the control information process. Finally, modelling should respond to the specific needs of virtual production in one-of-a-kind business, where, for example, the design of the production system accentuates.

Two sets of modelling tools were analyzed against this framework: comprehensive modelling approaches and specific, more partial tools for virtual, one-of-a-kind production. The analysis reveals that the comprehensive approaches tend to be biased towards particular aspects of production, especially the transformation model. Specific modelling tools, corresponding to all three views of production, can be found, which proves that these three views have been recognized as necessary and important from the practical point of view. These results suggest that, at the level of research, the search for a unified conceptualization of production should be emphasized; only based on such a foundation can truly comprehensive and integrated modelling tools be constructed (examples of such work provide $[10,11,15])$. At the practical level, modelling efforts - in lack of tools based on a unified conceptualization - have to be partial; however, these efforts should be structured so that various modelling approaches could more easily be interfaced with each other, and the limitations of the particular tools in use should be clearly recognized.

\section{REFERENCES}

[1] Akao, Yoji (ed.). 1990. Quality Function Deployment. Productivity Press. Cambridge, Ma. 369 p.

[2] Cook, H.E. 1997. Product Management - Value, quality, cost, price, profit and organization. Chapman \& Hall, London. 411 p.

[3] Ford, Henry. 1926. Today and Tomorrow. Doubleday, Page \& Co., Garden City. (Available as reprint edition: Productivity Press, Cambridge MA. 1988.) 286 p.

[4] GERAM: Generalised Enterprise Reference Architecture and Methodology. IFIP-IFAC Task Force. Version 1.6.3 (March 1999). 
[5] Gilbreth, Frank B. and Gilbreth, L.M. 1922. Process Charts and Their Place in Management. Mechanical Engineering, January, pp. 38 - 41, 70.

[6] Goldman, Steven L., Nagel, Roger N. \& Preiss, Kenneth. 1995. Agile Competitors and Virtual Organizations. Van Nostrand Reinhold, New York. 414 p.

[7] Hopp, Wallace \& Spearman, Mark. 1996. Factory Physics: Foundations of Manufacturing Management. Irwin/McGraw-Hill, Boston. 668 p.

[8] ISO TC184/SC5/WG1. 1999. Industrial Automation systems - Concepts and rules for enterprise models. 1999-April-14 version. Captured from http://www.mel.nist.gov/sc5wg1/std-dft.htm, March 3, 2000.

[9] Jarke, Matthias. 1998. Requirements Tracing. Communications of the ACM, Vol. 41, No. 12 , pp. 32-36.

[10] Kang, H.W., Kim, J.W. \& Park, S.J. 1998. Integrated Modelling Framework for Manufacturing Systems: A Unified Representation of the Physical Process and Information System. The International Journal of Flexible Manufacturing Systems, 10, 231-265.

[11] Karhu, Vesa. Forthcoming. Proposed new method for construction process modelling. International Journal of Computer Integrated Design and Construction.

[12] Koskela, Lauri. 2000. An exploration towards a production theory and its application to construction. Espoo, VTT Building Technology. 296 p. VTT Publications; 408 ISBN 951-38-5565-1; 951-38-5566-X WW: http://www.inf.vtt.fi/pdf/publications/2000/P408.pdf

[13] Laurikkala, Heli, Tanskanen, Kari, Nevalainen, Paavo, Vainio-Mattila, Markus. 1999. Consortium as a Virtual Enterprise in Project Planning. The 5th International Conference on Concurrent Engineering, The Hague, The Netherlands, 15-17 March 1999.

[14] Malone, Thomas W., Crowston, Kevin, Lee, Jintae, Pentland, Brian, Dellarocas, Chrysanthos, Wyner, George, Quimby, John, Osborn, Charles S., Bernstein, Abraham, Herman, George, Klein, Mark, O'Donnell, Elissa. 1999. Tools for Inventing Organizations: Toward a Handbook of Organizational Processes. Management Science, Vol. 45, No. 3, pp. 425-443.

[15] Park, H. \& Cutkosky, M.R. 1999. Framework for Modelling Dependencies in Collaborative Engineering Processes. Research in Engineering Design 11:84-102.

[16] Porter, M. 1985. Competitive Advantage. The Free Press. 557 p.

[17] Ramesh, Balasubramaniam. 1998. Factors Influencing Requirements Traceability Practice. Communications of the ACM, Vol. 41, No. 12, pp. 37-44.

[18] Riis, Jens, Mortensen, Harry \& Johansen, John. 1992. A new concept for managing oneof-a-kind production. In: 'One-of-a-kind production': New approaches. Hirsch, B.E. \& Thoben, K.-D. (Ed.). Elsevier Science, Amsterdam. Pp. 195 - 208.

[19] Rose, Thomas. 1998. Visual Assessment of Engineering Processes in Virtual Enterprises. Communications of the ACM, Vol. 41, No. 12, pp. 45-52.

[20] Schlenoff, Craig, Knutilla, Amy, Ray, Steven. 1996. Unified Process Specification Language: Requirements for Modelling Processes. National Institute of Standards and Technology.

[21] Shewhart, W.A. 1931. Economic Control of Quality of Manufactured Product. Van Nostrand, New York. $501 \mathrm{p}$.

[22] Wortmann, J.C. 1992. Factory of the Future: Towards an integrated theory for one-of-akind production. In: 'One-of-a-kind production': New approaches. Hirsch, B.E. \& Thoben, K.-D. (Ed.). Elsevier Science, Amsterdam. Pp. 37 - 74. 